\title{
Forkhead Box Transcription Factor (FOXO3a) mediates the cytotoxic effect of vernodalin in vitro and inhibits the breast tumor growth in vivo
}

Suresh Kumar Ananda Sadagopan ${ }^{1,2^{*}+}$, Nooshin Mohebali ${ }^{1 \dagger}$, Chung Yeng Looi ${ }^{1}$, Mohadeseh Hasanpourghadi ${ }^{1}$, Ashok Kumar Pandurangan ${ }^{1}$, Aditya Arya ${ }^{3}$, Hamed Karimian$^{3}$ and Mohd Rais Mustafa ${ }^{1}$

\begin{abstract}
Background: Natural compounds have been demonstrated to lower breast cancer risk and sensitize tumor cells to anticancer therapies. Recently, we demonstrated that vernodalin (the active constituent of the medicinal herb Centratherum anthelminticum seeds) induces apoptosis in breast cancer cell-lines. The aim of this work was to gain an insight into the underlying anticancer mechanism of vernodalin using in vitro and in vivo model.

Methods: Vernodalin was isolated through the bioassay guided fractionation from the seeds. The protein expression of p-Akt, PI3K, FOXO3a, Bim, p27kip1, cyclinD1, and cyclinE was examined by the Western blot analysis. Immunoprecipitation assays were performed to analyse Akt kinase activity. Small interfering RNA (siRNA) was used to study the role of $\mathrm{FOXO} 3$ a upregulation and their targets during vernodalin treatment. Immunofluorescence, subcellular localisation of FOXO3a by Western blot was performed to analyse FOXO3a localisation in nucleus of breast cancer cells. Immunohistochemical analysis of PCNA, Ki67, p27kip1, FOXO3a and p-FOXO3a in the LA7-induced mammary gland tumor model was performed.

Results: Our results showed that vernodalin regulates cancer cell apoptosis through activation of FOXO transcription factors and its downstream targets (Bim, p27Kip1, p21Waf1/cip1, cyclin D1, cyclin E) as examined by Western blots. Furthermore, we showed that FOXO3a/PI3K-Akt played a significant role in vernodalin induced apoptosis in breast cancer cells. Immunoprecipitation assays showed Akt kinase activity was downregulated. Immunofluorescence, subcellular fractionation and Western blot showed FOXO3a accumulation in the nucleus of breast cancer cells after vernodalin treatment. Silencing of FOXO3a protected breast cancer cells against vernodalin induced apoptosis. The anti-tumor action of vernodalin was further confirmed by examining cell proliferative markers, PCNA and Ki67 in the LA7-induced mammary gland tumor model. We also corroborated our findings in vivo by showing upregulation of p27Kip1, FOXO3a and decrease in the p-FOXO3a level in vernodalin-treated breast tumor tissue.
\end{abstract}

Conclusions: Our results suggest that PI3K-Akt/FOXOa pathway is a critical mediator of vernodalin-induced cytotoxicity and this compound could be further developed as a potential chemopreventive or chemotherapeutic agent for breast cancer therapy.

Keywords: Breast cancer, Vernodalin, Cancer prevention, FOXO3a, Akt

\footnotetext{
* Correspondence: asureshphd@gmail.com

${ }^{\dagger}$ Equal contributors

'Department of Pharmacology, Faculty of Medicine, University of Malaya,

Kuala Lumpur 50603, Malaysia

${ }^{2}$ Department of Biochemistry, Central Leather Research Institute, Council of

Scientific and Industrial Research (CSIR), Adyar, Chennai 600 020, India

Full list of author information is available at the end of the article
}

\section{Biomed Central}

(c) 2015 Ananda Sadagopan et al. Open Access This article is distributed under the terms of the Creative Commons Attribution 4.0 International License (http://creativecommons.org/licenses/by/4.0/), which permits unrestricted use, distribution, and reproduction in any medium, provided you give appropriate credit to the original author(s) and the source, provide a link to the Creative Commons license, and indicate if changes were made. The Creative Commons Public Domain Dedication waiver (http://creativecommons.org/publicdomain/zero/1.0/) applies to the data made available in this article, unless otherwise stated. 


\section{Background}

Breast cancer is the third leading cause of cancer deaths and highest among women aged between 20 and 59 years based on a cancer statistics in 2013 [1]. It is still the leading cause of morbidity and mortality of women worldwide; with $23 \%$ (1.38 million) of new cancer cases and $14 \%(458,400)$ of the total cancer deaths [2]. Breast cancer development and metastasis is a multistep process, often caused by dysfunction of several regulatory features those keep cells in check [3]. Continents such as North America, Western Europe and Australia have been reported to have the highest incidence rates. Nevertheless, it is increasing in all parts of the globe, especially in the developing countries. Steroid hormones, particularly estrogen, contribute to the development and progression of mammary gland neoplasia. Majority of breast cancer is sporadic and the risk factors are mostly linked to estrogen exposure and age [4]. The outcome of breast cancer treatment during the past several years has significant improvement, primarily due to early diagnosis and chemotherapies. However, there is a relative lack of effective therapies for advanced-stage metastatic disease [5].

Most of the chemo-therapeutic drugs in market for treating breast cancer cause harmful effects such as severe nausea, vomiting, fatigue and hair loss. Hence, there is an urgent need to develop alternative therapeutic drugs with negligible side effects. One such alternative could be the use of plant based chemo-therapeutic drugs. Natural products, including phytoconstituents and dietary agents have already been shown to suppress the growth of breast tumor cells through modulation of cell proliferation, cellular differentiation, apoptosis, angiogenesis as well as several signal transduction pathways $[6,7]$. Certain natural products are used in cancer chemo-prevention to inhibit or revert carcinogenesis and to suppress cancer malignancy [8]. The efficacy of several dietary supplements and natural products in breast cancer has been tested by clinical intervention trials that support these potential utility of these agents in the breast cancer prevention, treatment, and management regimens in the future [9]. In addition, epidemiological data suggest that consumption of plant foods or natural products $(47.2 \%)$ and botanical supplements (47.5\%) that contain high levels of antioxidants can slow down or prevent the appearance of cancer $[10,11]$.

ForkheadboxO (FOXO) proteins, a subgroup of the forkhead transcription factors, play an important role in tumor suppression mainly by upregulating target genes involved in cell cycle arrest and apoptosis [12]. In mammals, this family of proteins consists of four membersFOXO1, FOXO3, FOXO4 and FOXO6, and accumulated evidence shows that FOXO3a regulates a wide range of biological processes, including proliferation, apoptosis, protection against oxidative stress, and metabolism [13].
In particular one of the FOXO members, FOXO3a is under-expressed in many breast cancer patients [14]. Low levels of FOXO3 have been reported to confer chemotherapy resistance in human cancers, being significantly associated with poor prognosis in cancer patients $[15,16]$. FOXO3a regulation and activity depends mainly on the subcellular localisation, which can be achieved via post-translational modifications including phosphorylation, acetylation and ubiquitination [17]. Several studies indicate that the FOXO family is a key downstream target of PI3K-Akt pathway in development and longevity [18, 19]. Akt controls transcription of FOXO3a target genes, through modulation of FOXO3a activity by phosphorylating three conserved threonine/ serine residues (Thr-32, Ser-253, and Ser-315), leading to the release of FOXO3a from DNA and translocation to the cytoplasm $[20,21]$. Reports suggest that up regulation of FOXO3a proteins can promote apoptosis through upregulation of the pro-apoptotic Bcl-2 family member (Bim) and consequent increase in the cell cycle protein levels of p27kip1. In contrast a CDK inhibitor, (CKI) is capable of associating with cyclin-CDK complexes and inhibits the apoptosis [22-24]. Therefore, FOXO3a has been proposed as an important factor influencing the efficacy of a variety of chemotherapeutic drugs. In fact, the restoration of FOXO3a expression has been exploited for some mechanism-based anticancer therapies $[25,26]$.

Cells replicate their genome and divide by the cell cycle process. During this process, the cell cycle control is a cyclically operating biochemical device consisted of numerous interacting proteins, which induce and organize proper progression, including cyclins, cyclin-dependent kinases (CDK) and their inhibitors (CDKI) [27, 28]. Dysregulation of these regulators could give rise to cell growth uncontrollably. PI3K/Akt signaling pathway is a vital transduction pathway in regulating cell cycle and apoptosis. Different types of cancer, including human breast cancer and lung cancer, reportedly activate this pathway [29]. Recent studies have shown that some anti-cancer drugs could down-regulate Akt to induce G1/S arrest [30, 31]. Overactive PI3K/Akt pathway decreases apoptosis and tumor cell cycle arrest, which leads to growth or proliferation of cancer. Akt phosphorylates GSK3 $\beta$ and blocks its kinase activity, thereby allowing cyclin D1 to accumulate which could inhibit cells into $S$ period from G1 phase. Akt can also negatively influence the expression of cell cycle inhibitors such as KIP1 (also known as p27) and WAF1 (also known as CIP1 or p21) [32].

Centratherum anthelminticum (L.) Kuntze, (plant name has been confirmed with www.theplantlist.org) generally known as kalajiri, somraj, black cumin or bitter cumin, is a member of Asteraceae family. The seeds of C. anthelminticum have been reported to have various 
pharmacological properties, such as anti-viral, anti-filarial, anti-microbial, anti-fungal and anti-diabetic activities [33-35]. We recently reported that the chloroform fraction of $C$. anthelminticum seeds exhibited anti-oxidant property by inhibiting tumor necrosis factor- $\alpha$, and inhibiting breast cancer cells growth by interrupting the activation of nuclear factor-kappa B [36]. Our earlier report demonstrated that vernodalin (the active compound isolated through bioassay guided fractionation) can induce apoptosis in human breast cancer cells via caspase pathway [37]. Vernodalin (colourless oil) is a cytotoxic sesquiterpene lactone having two active $\alpha, \beta$-unsaturated enoate moieties (one on the lactone ring and the other on the side chain). However, the molecular aspect of vernodalin and its in vivo anti-tumor efficacy have not been studied. This present study seek to investigate the cellular mechanisms underlying the cytotoxicity effect of vernodalin in human breast cancer cell lines and rat LA7 induced mammary gland tumor model. Our results suggest that FOXO3a is a key mediator of vernodalin induced cell cycle arrest and apoptosis in breast cancer cells.

\section{Methods}

\section{Plant material}

The seeds of $C$. anthelminticum were procured from the medicinal plant cultivation zone of Amritum BioBotanica Herbs Research Laboratory Pvt. Ltd, Betul Madhya Pradesh India. Voucher specimen (CA-9) was deposited ( $9^{\text {th }}$ August 2008) in the Department of Pharmacology, University Malaya.

\section{Extraction and isolation}

The powdered seeds of $C$. anthelminticum (150 g) were extracted successively with chloroform $\left(\mathrm{CHCl}_{3}\right)$ (3X250ml) (Merck, Darmstadt, Germany) in a Soxhlet apparatus for $24 \mathrm{~h}$. The extracts were collected, filtered and concentrated to dryness under reduced pressure in a rotary evaporator $\left(<40{ }^{\circ} \mathrm{C}\right)$ under vacuum to yield $8.53 \mathrm{~g}$. Then the dried samples were fractionated into six fractions using High Performance Liquid Chromatography (HPLC) as described previously [37]. The chemical structure of vernodalin was shown in the Additional file 1: Figure S1. The fraction containing vernodalin were further subjected to HPLC isolation until $>90 \%$ pure. The purified compound, vernodalin was confirmed through spectral analysis as done in our previous publication [37].

\section{Cell culture}

The human breast cancer cell lines, (MCF-7; MDA-MB 231) and rat mammary tumor cell line (LA7) were purchased from the American Type Culture Collection (ATCC, Manassas, VA, USA). Cells were cultured in Dulbecco's Modified Eagle Medium (Gibco BRL, Carlsbad, CA, USA) supplemented with $10 \%$ heat-inactivated fetal bovine serum, $2 \mathrm{mM}$ glutamine, $1 \%$ penicillin and streptomycin. LA7 cells were maintained in Dulbecco's Modified Eagle's Medium supplemented with $5 \%$ fetal bovine serum, $1 \%$ penicillin and streptomycin, $4.5 \mathrm{~g} / \mathrm{L}$ glucose, $0.005 \mathrm{mg} / \mathrm{mL}$ insulin, and $20 \mathrm{mM}$ HEPES in humidified environment with $5 \% \mathrm{CO}_{2}$ at $37{ }^{\circ} \mathrm{C}$. For experimental purposes, cells in exponential growth phase (approximately 70-80 \% confluency) were used.

\section{Immunofluorescence analysis of $\mathrm{FOXO} 3$}

$1 \mathrm{X} 10^{4}$ cells per well were seeded onto 96-well plate. Cells were treated with vernodalin or DMSO (negative control) and Doxorubicin (Purchased from Pfizer, USA) at indicated concentrations for $24 \mathrm{~h}$. The vernodalin concentration and time was fixed based upon our previous publication [37]. Cells were fixed with $4 \%$ formaldehyde for $15 \mathrm{~min}$. Fixed cells were permeabilized with $0.1 \%$ Triton X-100 in phosphate buffer saline (PBS). Samples were blocked with $3 \%$ bovine serum albumin and incubated with FOXO3a primary rabbit antibody (Cell Signaling Technology, Danvers, MA) for $1 \mathrm{~h}$. Samples were washed three times with wash buffer I (1 X PBS) before addition of goat anti rabbit secondary antibodies conjugated with DyLight ${ }^{\mathrm{Tm}} 488$ (Thermo Scientific). Cells were rinsed three times with wash buffer II (1 X PBS with $1 \%$ Tween-20). Nucleus was stained with Hoechst 33258. Stained cells were visualized and images were captured using Cellomics ArrayScan HCS reader (Thermo Scientific, USA). Cell health profiling bioapplication module was used to quantify the fluorescence intensities of each dye.

\section{Protein extraction}

Cells treated with or without vernodalin for $24 \mathrm{~h}$ were collected and lysed in cell lysis buffer (1 \% NP- $40,0.5 \%$ sodium deoxycholate, $0.1 \%$ SDS) supplemented with freshly added $10 \mathrm{mM} \beta$-glycerophosphate, $1 \mathrm{mM}$ sodium orthovanadate, $10 \mathrm{mM} \mathrm{NaF}, 1 \mathrm{mM}$ phenylmethylsulfonyl fluoride and Protease Inhibitor Cocktail (Santa Cruz, CA) for $30 \mathrm{~min}$ on ice. Then lysates were centrifuged at $12,000 \times \mathrm{g}$ for $30 \mathrm{~min}$ at $4{ }^{\circ} \mathrm{C}$. The concentration of total protein was determined by Bradford assay (Bio-Rad, Hercules, CA). The protein extracts were stored at $-80{ }^{\circ} \mathrm{C}$ until further processing.

\section{Westernblot analysis}

The extracts are heated in a boiling water bath for $5 \mathrm{~min}$ and equal amounts of protein $(40 \mu \mathrm{g})$ were separated by $10 \%$ polyacrylamide gel. Proteins were then transferred to microporous polyvinylidene difluoride (PVDF) membrane (Milipore). Membranes were incubated in $5 \%$ BSA (Sigma) blocking buffer for $1 \mathrm{~h}$ at room temperature. Incubations with primary antibody were carried out overnight at $4{ }^{\circ} \mathrm{C}$. Immunoblotting was performed with the following antibodies: anti-FOXO3a, 
anti-p-FOXO3a (Ser-253), anti-p21Cip1/waf1, antip27Kip1, anti-Bim, anti-cyclinD1, anti-cyclinE, anti-Akt (total), anti-p-Akt (Thr-308), anti-p-PI3K, anti-totalPI3K, anti-GAPDH, anti-LaminB1 (1:1000) (Cell Signaling Technology, Danvers, MA) and mouse anti- $\beta$-actin (1:10000) (Sigma) antibodies overnight at $4{ }^{\circ} \mathrm{C}$. The next day, the membranes were washed three times for $10 \mathrm{~min}$ in TBS-T and incubated with the corresponding horseradish peroxidase-conjugated secondary antibody for $1 \mathrm{~h}$. To remove excess antibodies, membranes were washed 4 times before HRP activities were detected using ECL Plus Chemiluminescence Reagent (Amersham, Chalfont, UK) according to the protocol supplied with the kit. Finally the quantification was done by ImageJ software (NIH, Bethesda, MD).

\section{Akt kinase activity}

After appropriate treatments, Akt kinase assay was performed using a non-radioactive Akt kinase assay kit (Cell Signaling Technology) following the manufacturer's instructions. Briefly, Akt was immunoprecipitated from $100 \mu \mathrm{g}$ cell lysate overnight using an immobilized Akt antibody. The beads were then pelleted and washed twice in $500 \mu \mathrm{L}$ of cell lysis buffer and twice in $500 \mu \mathrm{L}$ of kinase buffer. Pellets were resuspended in $25 \mu \mathrm{L}$ of kinase buffer containing $0.5 \mathrm{~mL}$ of $10 \mathrm{mM}$ ATP, $1 \mathrm{mg}$ Glycogen synthase kinase-3 (GSK-3) fusion protein for $30 \mathrm{~min}$ at $30^{\circ} \mathrm{C}$. Kinase reaction was terminated by adding sample buffer containing $\beta$-mercapatoethanol. Finally, the activity of Akt kinase in each sample was determined according to GSK- $3 \alpha / \beta$ phosphorylation by Western blot.

\section{Preparation of cytosol/nuclear extract}

At $24 \mathrm{~h}$ after treatment, the MCF-7 and MDA- MB 231 cells were harvested and washed 3 times with cold phosphate-buffered saline (PBS). The cytoplasmic and nuclear protein fractions were extracted using NE-PER nuclear/cytoplasmic extraction reagent (Cell Signalling Technology). In brief $5 \times 10^{6}$ cells is pelleted by centrifugation at $500 \times \mathrm{g}$ for $2-3 \mathrm{~min}$. The cell pellet were treated with ice-cold $500 \mu \mathrm{l}$ of CER I (cytoplasmic extraction reagent 1) then vortex the tube vigorously on the highest setting for $15 \mathrm{~s}$ to fully suspend the cell pellet. Incubate the tube on ice for $10 \mathrm{~min}$ then add icecold $27.5 \mu \mathrm{l}$ of CER II to the tube then vortex the tube for $5 \mathrm{~s}$ on the highest setting. Incubate tube on ice for $1 \mathrm{~min}$; centrifuge the tube for $5 \mathrm{~min}$ at maximum speed in a microcentrifuge $(\sim 16,000 \times \mathrm{g})$. Immediately transfer the supernatant (cytoplasmic extract) to a clean prechilled tube the insoluble (pellet) fraction which contains nuclei treated with ice-cold $250 \mu \mathrm{l}$ NER (nuclear extraction reagent) keep the sample on ice and continue vortexing for $15 \mathrm{~s}$ every $10 \mathrm{~min}$, for a total of $40 \mathrm{~min}$ then centrifuged at maximum speed $(\sim 16,000 \times \mathrm{g})$ in a microcentrifuge for $10 \mathrm{~min}$. Immediately transfer the supernatant (nuclear extract) fraction to a clean pre-chilled tube. Store extracts at $-80{ }^{\circ} \mathrm{C}$ until use. Cytoplasmic and nuclear protein extracts were used for Western blot analysis.

\section{Gene silencing with small interfering RNAs (FOXO3a)}

MCF-7/MDA-MB231 cells were cultured in six-well plates until $60 \%$ confluent and were transfected with 1 $\mu \mathrm{g}$ of SiRNA duplex and scrambled oligonucleotides using SiRNA transfection reagent (Sigma Aldrich sc37887) according to the manufacturer's instructions. $48 \mathrm{~h}$ after transfection, cells were treated with vernodalin or DMSO vehicle for $24 \mathrm{~h}$. Then the cells were collected for Western blot analysis.

\section{Cell cycle analysis}

Cell cycle analysis was performed using propidium iodide staining as described previously with slight modifications [37]. Briefly, after silencing with FOXO3a cells were washed in PBS and fixed in $90 \%$ ethanol. Fixed cells were then washed twice in PBS and stained in $50 \mu \mathrm{M}$ propidium iodide containing $5 \mu \mathrm{g} / \mathrm{ml}$ DNase-free RNase for $1 \mathrm{~h}$, then analyzed by flow cytometry using a FACS Canto II flow cytometer (BD Biosciences, USA).

\section{Experimental animals and diet}

The animal protocol was approved by the Institutional Animal Use and Care Committee of the University of Malaya (2014-05-07/PHAR/R/CYL). Pathogen-free female Sprague-Dawley rats (6 weeks old) were obtained from the Animal House, Faculty of Medicine, University of Malaya, Kuala Lumpur. The animals were acclimatized to standard laboratory conditions including a controlled environment at $24 \pm 1{ }^{\circ} \mathrm{C}$ and $50 \pm 10 \%$ relative humidity with the alternating 12:12-h dark-light cycle for 1 week before the beginning of the study and provided with standard food pellets and tap water ad libitum.

\section{Cell preparation and mammary tumor induction}

When the cells (LA7) were $90 \%$ confluent, the medium was removed and the cells washed with PBS to remove dead and undetached cells. Low amount of trypsinEDTA was added to detach cells. Cells were obtained immediately by centrifugation at $100 \mathrm{~g}$ for $10 \mathrm{~min}$ at $4{ }^{\circ} \mathrm{C}$, washed twice with PBS and dispersed. For viability detection, the cells were stained with trypan blue and counted using a hemocytometer. Cells were eventually suspended in $300 \mu \mathrm{L}$ of PBS. All harvested cells were used within $1 \mathrm{~h}$ of preparation. After one week acclimation period, rats were anesthetized using an intraperitoneal (i.p.) injection with a mixture of ketamine- $\mathrm{HCl}(150 \mathrm{mg} / \mathrm{kg}$ body weight) and xylazine $(10 \mathrm{mg} / \mathrm{kg}$ body weight). The LA7 cells 
(300 $\mu \mathrm{L}$ containing $5 \times 10^{6}$ cells) were inoculated subcutaneously into the mammary fat pad (left flank) of rats using a tuberculin syringe and $21 \mathrm{G}$ needle to initiate tumor growth. A total of twenty five female SD rats have been used in this study. The animals were divided into five groups $(n=5)$, where the Group (I) animals were kept as the normal control group (NC) and received i.p. injection of saline $(300 \mu \mathrm{l})$ and served as a control. Group (II) animals were classified as LA7-induced tumor control group (TC). Groups (III) represent the low dose treatment of vernodalin in tumor bearing animals (TT+ $1 \mathrm{mg} / \mathrm{kg}$-Vernodalin), Groups (IV) represent the high dose treatment of vernodalin in tumor bearing animals (TT+ $10 \mathrm{mg} / \mathrm{kg}$-Vernodalin), and Group (V) represent the Tamoxifen treatment in tumor bearing animals (TT+ $1 \mathrm{mg} / \mathrm{kg}$ Tamoxifen). For Group III to $\mathrm{V}$ the Vernodalin and Tamoxifen (from Sigma Aldrich, USA) were dissolved in saline separately and the treatment was performed by intraperitoneal (i.p.) injection three times/week after the appearance of tumor (approximate size is $2 \mathrm{~cm}$ in 2 weeks) for another three weeks. The body weight of each rat was recorded weekly. At the end of the experimental period (After five weeks), rats were fasted overnight and the body weight of each rat was monitored. Then, the rats were anaesthetized and sacrificed by decapitation. Mammary tissue samples were obtained washed twice with ice-cold $0.1 \mathrm{M}$ phosphate buffered saline (PBS), weighed and fixed in $10 \%$ neutralbuffered formalin for immunohistochemical analyses.

\section{Tumor growth and measurement}

The latency period and tumor incidence was determined as tumor growth landmarks [38]. All animals were monitored for mammary tumor development. Tumor diameters and animal weight were measured every week. The tumor mass was measured horizontally and vertically using a digital caliper. Volume of tumor (V) was calculated by the formula determined by Carlsson: $\mathrm{V}=(\mathrm{ab} 2) / 2$, where ' $a$ ' and ' $b$ ' is the longest and shortest diameters of the tumor, respectively [39].

\section{Histopathological examination}

Kidney and liver tissues were fixed in $10 \%$ buffered formalin, embedded in paraffin using a conventional automated system. The blocks were cut to obtain $5 \mathrm{~mm}$ thick sections and stained with hemotoxylin-eosin. Serial paraffin sections of each tissue image were captured by light microscopy (Nikon XDS-1B).

\section{Immunohistochemical analysis}

Paraffin embedded tissue sections of $5 \mu \mathrm{m}$ thickness were rehydrated first in xylene and then in graded ethanol solutions. Then, the slides were incubated with the
HistoVT (10x, pH 7.0) (Nacali Tesque, Tokyo, Japan) antigen retrieval solution for $20 \mathrm{~min}$ in $90{ }^{\circ} \mathrm{C}$ followed by cooling in room temperature. Next, the slides were blocked with $5 \%$ BSA in Tris-buffered saline-Tween 20 (TBS-T) for $2 \mathrm{~h}$ before the sections were immunostained with primary antibodies of PCNA, Ki67, FOXO3a, pFOXO3a and p27Kip1 (Cell Signaling Technology, USA) diluted 1:100 with $5 \%$ BSA in TBS-T and incubated overnight at $4{ }^{\circ} \mathrm{C}$. After washing the slides thrice with TBS-T, the sections were incubated with respective secondary antibodies with $5 \%$ BSA in TBS-T and incubated for $2 \mathrm{~h}$ at room temperature. Sections were then washed with TBST and incubated for 5-10 min in a Peroxidase stain DAB kit as per the instructions provided by the manufacturer (Dako, Glostrup, Denmark). Counter staining was performed using hematoxylin (Cell Path, UK), and the slides were photographed in light microscope (BX51, Olympus, Japan).

\section{Statistical analysis}

Statistical analyses were processed according to conventional procedures using the Statistical Program of Social Sciences (SPSS) software for Windows, Version 12.0 (Post-hoc, Tukey's test). A $P$ value $<0.05$ was considered statistically significant.

\section{Results}

Effect of vernodalin treatment on $\mathrm{FOXO} 3$ and its downstream target molecules

Several studies showed that phytochemicals such as genistein exert anti-cancer effect via activation of FOXO3a signalling $[40,41]$. Therefore, in this study we embarked to evaluate whether vernodalin (a cytotoxic compound isolated from Centratherum anthelminticum seeds) could affect FOXO3a expression in human breast cancer cell-lines (MCF-7 and MDA-MB231). Our results showed that vernodalin dose dependently $(6.25,9.5$ and $12 \mu \mathrm{g} / \mathrm{ml}$ ) induced higher expression of FOXO3a in both MCF-7 and MDA-MB231 cells. In addition immunoblotting analysis showed a reduction of the phosphorylated forms of FOXO3a at the critical phosphorylation sites (Ser253) after vernodalin treatment $(6.25,9.5$ and $12 \mu \mathrm{g} / \mathrm{ml}$ ) as compared with untreated control cells (Fig. 1a and b). The cell cycle progression is regulated by cyclin/cyclin-dependent kinase (CDK) complexes, as the uncontrolled expressions of cyclins and/or CDKs may lead to cell cycle dysregulation and tumorigenesis. FOXO3a controls cell cycle progression by regulating the downstream expression level of cell cycle inhibitor p27Kip1 and p21 (Cip1/waf1). Results showed that p27Kip1 and p21Cip1/waf1 were up-regulated, whereas the levels of cyclin D1 and cyclin E were decreased in response to vernodalin treatment (Fig. 2a and b). Similarly, the pro-apoptotic protein Bim, another downstream 

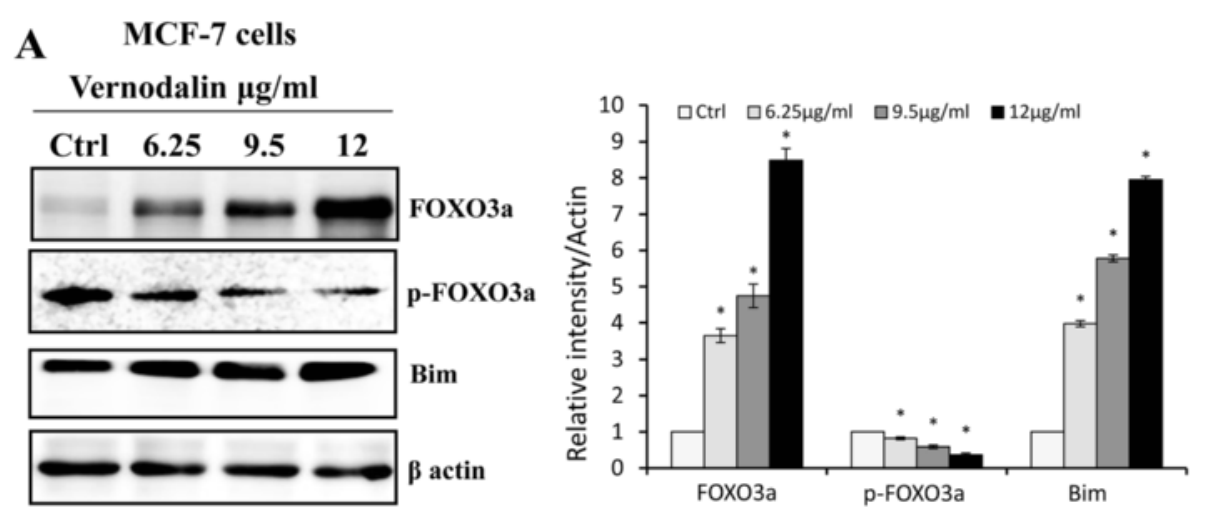

B MDA-MB 231 cells
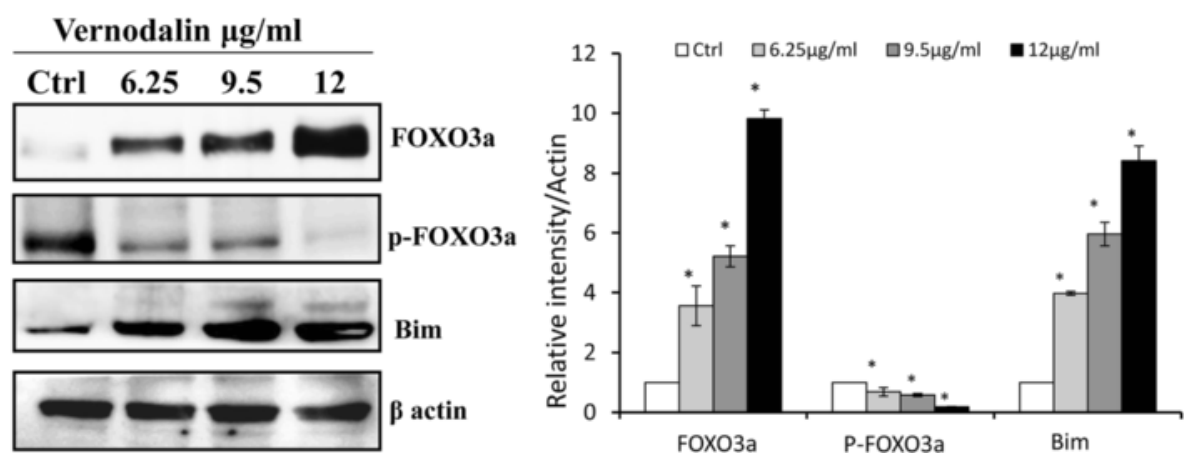

Fig. 1 Effect of Vernodalin on modulation of FOXO3a and Bim. Expression of FOXO3a/p-FOXO3a (Ser253) and Bim in breast cancer cells of MCF-7 (a) and MDA-MB231 (b). Whole cell lysates were prepared from the breast cancer cell lines after the vernodalin treatment for $24 \mathrm{~h}$. The expression of FOXO3a, phosphorylated FOXO3a, and Bim were analysed by Western blots as described in "Materials and Methods". $\beta$-actin was used as loading control. The data are representative of three experiments. Respective blots were quantified using ImageJ software. Data's are expressed as mean \pm S.D. All the treatment groups were compared with control. "**" denotes statistically significant at $P<0.05$

target of FOXO3a was increased in both breast cancerlines cells at $24 \mathrm{~h}$ after vernodalin treatment $(6.25,9.5$ and $12 \mu \mathrm{g} / \mathrm{ml}$ ) as compared with untreated control cells Fig. $1 \mathrm{a}$ and $\mathrm{b}$.

\section{FOXO3a subcellular localization is affected by vernodalin treatment}

Previously, we showed that FOXO3a is upregulated in vernodalin treated breast cancer cells. Next, we seek to investigate if vernodalin treatment could relocate FOXO3a protein to the nucleus in order to exert its function. We treated MCF-7 and MDA-MB231 cells with vernodalin for $24 \mathrm{~h}$ and the intracellular localization of FOXO3a was analysed by immunofluorescent staining. As shown in Additional file 2: Figure S2 and Additional file 3: Figure $\mathrm{S} 3$, FOXO3a resided in the cytoplasm, with negligible nuclear staining in control untreated cells. Interestingly, vernodalin treatment induced a change in the subcellular localization of FOXO3a, with a significant proportion of the protein being translocated to the nucleus after $24 \mathrm{~h}$ treatment, comparable to standard drug Doxorubicin
(Additional file 2: Figure S2 and Additional file 3: Figure S3). To confirm this, we performed nuclear/cytoplasmic fractionation of breast cancer cells treated with vernodalin. Western blot results showed higher expression of FOXO3a in the nucleus compared with the cytoplasmic fractionation after vernodalin treatment in MCF-7 and MDA-MB231 cells (Fig. 3). This correlates with nuclear translocation of the FOXO3a transcription factor that may contribute to FOXO3a activation and induction of cell death during vernodalin treatment.

FOXO3a silencing by siRNA abrogates vernodalin-induced cell death

In order to confirm the relevance of FOXO3a in vernodalin mediated apoptosis, we performed gene silencing experiments by transfecting MCF-7 and MDA-MB231 cells with siRNA specific for FOXO3a. As shown in Fig. 4a, vernodalin treated or control siRNA transfected cells have higher FOXO3a protein level. In contrast, FOXO3a silencing by siRNA abrogated vernodalininduced expression of FOXO3a protein as determined 


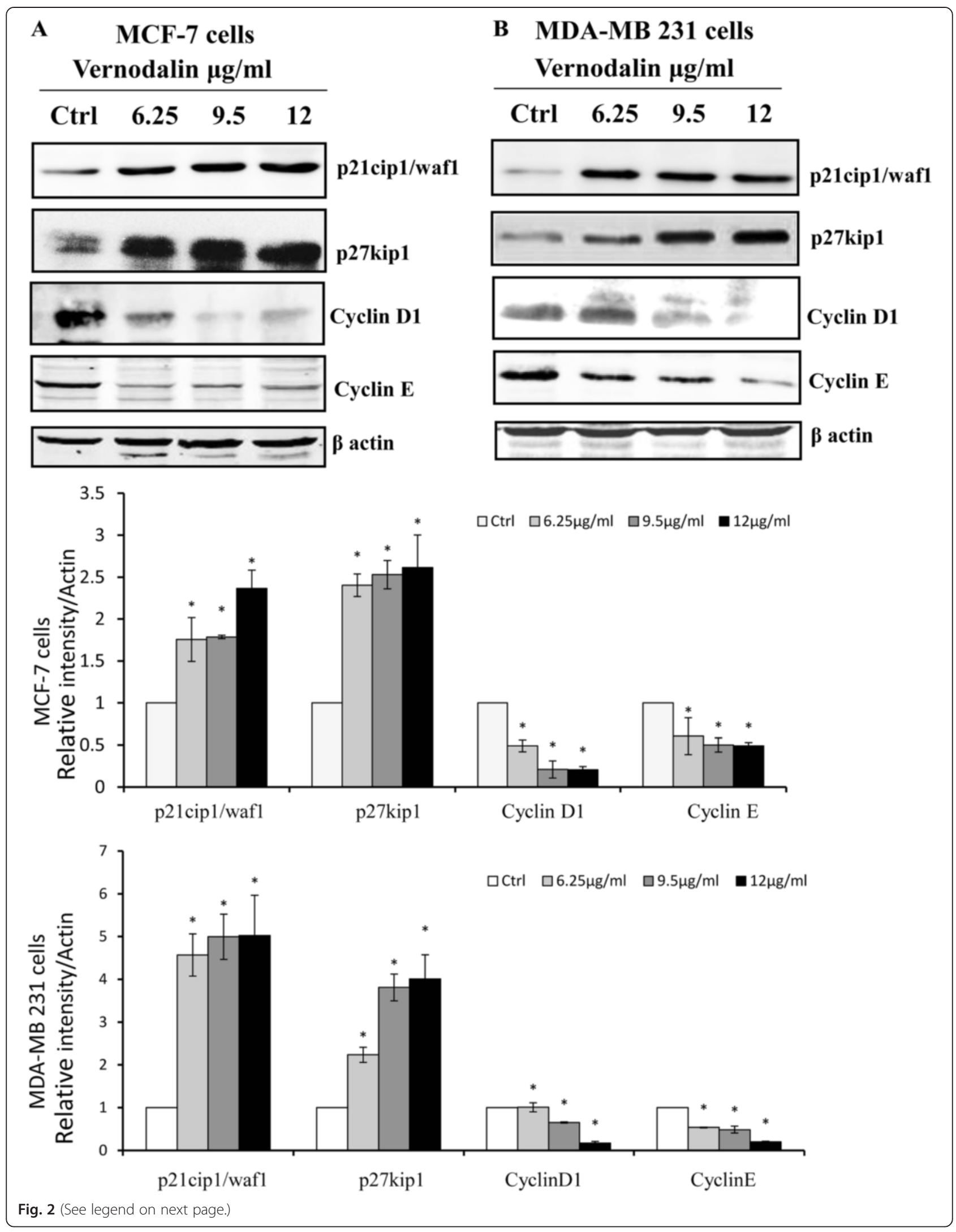


(See figure on previous page.)

Fig. 2 Effect of Vernodalin on modulation of cell cycle proteins. a \& b Shows the Western blots expression of p27kip1, p21cip1/waf1, cyclin D1 and cyclin E in breast cancer cells of MCF-7 and MDA-MB231. $\beta$-actin was used as loading control. The data are representative of three experiments. Respective blots were quantified using ImageJ software. Data's are expressed as mean \pm S.D. All the treatment groups were compared with control. "*" denotes statistically significant at $P<0.05$

by Western blot. In addition, cell cycle analysis showed that silencing of FOXO3a by siRNA can partially rescue cells from vernodalin-mediated cell apoptosis. This is evident from the decrease in the proportion of cells in the sub-G1 phase in siFOXO3a-transfected breast cancer cells when compared with the control siRNA-transfected cells (Fig. $4 \mathrm{~b}$ and c). To further show that FOXO3a has an essential role in response to vernodalin treatment, we transfected the MCF-7 and MDA-MB231carcinoma cells with either a FOXO3a-specific siRNA or control siRNA and studied the levels of cell cycle regulatory proteins after vernodalin treatment. Western blots analysis showed that the FOXO3a-specific siRNA, but not control siRNA, inhibited the induction of p27Kip1, p21cip1/waf1, and increased the cyclin D1 protein levels (Fig. 4d and e). These results suggested that vernodalin targets FOXO3a to mediate apoptosis in breast cancer cells.

\section{Vernodalin-induced activation of FOXO3a is dependent on PI3K/Akt signaling pathway}

In our study, we examined the role of vernodalin on PI3K/Akt signaling in both breast cancer cell-lines. In

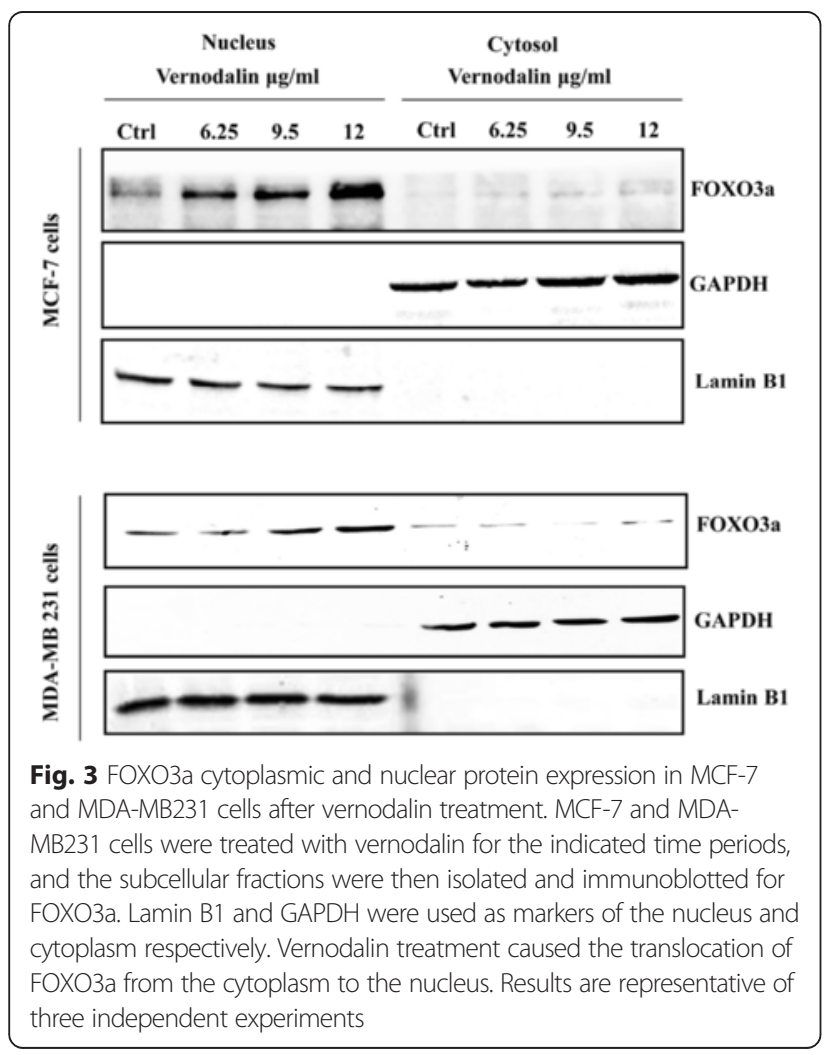

control cells, Akt and PI3K are predominantly activated, while vernodalin treatment markedly reduced the phosphorylation of Akt and PI3K as compared with control (Fig. 5a and b). This correlates with our previous Western blot data, which showed vernodalin treatment, lead to decrease level of p-FOXO3a. The Akt kinase activity was further assessed by the phosphorylation of GSK-3 protein through immunoprecipitation and Western blots. Immunocomplex kinase assay of Akt revealed that treatment with vernodalin for $24 \mathrm{~h}$ significantly abolished Akt kinase activity in MCF-7 and MDA-MB231 cells (Additional file 4: Figure S4). We have also checked whether any feedback regulation during FOXO3a silencing and analysed the protein levels of Akt and p-Akt during vernodalin treatment in control, FOXO3a specific siRNA and we could not find the significant changes in regarding with the feedback regulation (Additional file 5: Figure S5). Taken together, these observations suggest the importance of Akt signaling cascade in the activation of transcription factor FOXO3a and the extent of cell death caused by vernodalin in MCF-7 and MDAMB231 cells.

\section{Tumor development, body weight, tumor size and volume}

During the experimental period, the rats tolerated the subcutaneous administration of LA7 rat mammary tumor cells and vernodalin treatment by intraperitoneal injection. There were no clinical signs of toxicity related death in experimental groups. Histology of the liver and kidney tissues after vernodalin treatment $(1 \mathrm{mg} / \mathrm{kg}$ and $10 \mathrm{mg} / \mathrm{kg}$ ) was shown in the Additional file 6: Figure S6. As hematoxylin-eosin (H-E) staining these organs did not revealed histopathological abnormalities, degeneration, lesions or necrosis during the treatment. Liver sections of control and vernodalin treated rats exhibiting a concentric arrangement of the hepatocytes with sinusoidal cards around the central vein and portal tracts. Kidney sections of control and vernodalin treated rats showing normal renal tubules, corticomedullary junction, and glomeruli within the cortex region. The breast tumors started to develop within 7-10 days after LA7 cells injection. The body weight, tumor volume and the tumor percentage (\%) of control and treated animals is represented in Table 1. There was no significant body weight decreases in the tumor bearing rats (Group II-V) when it was compared with control rats (Group I). 


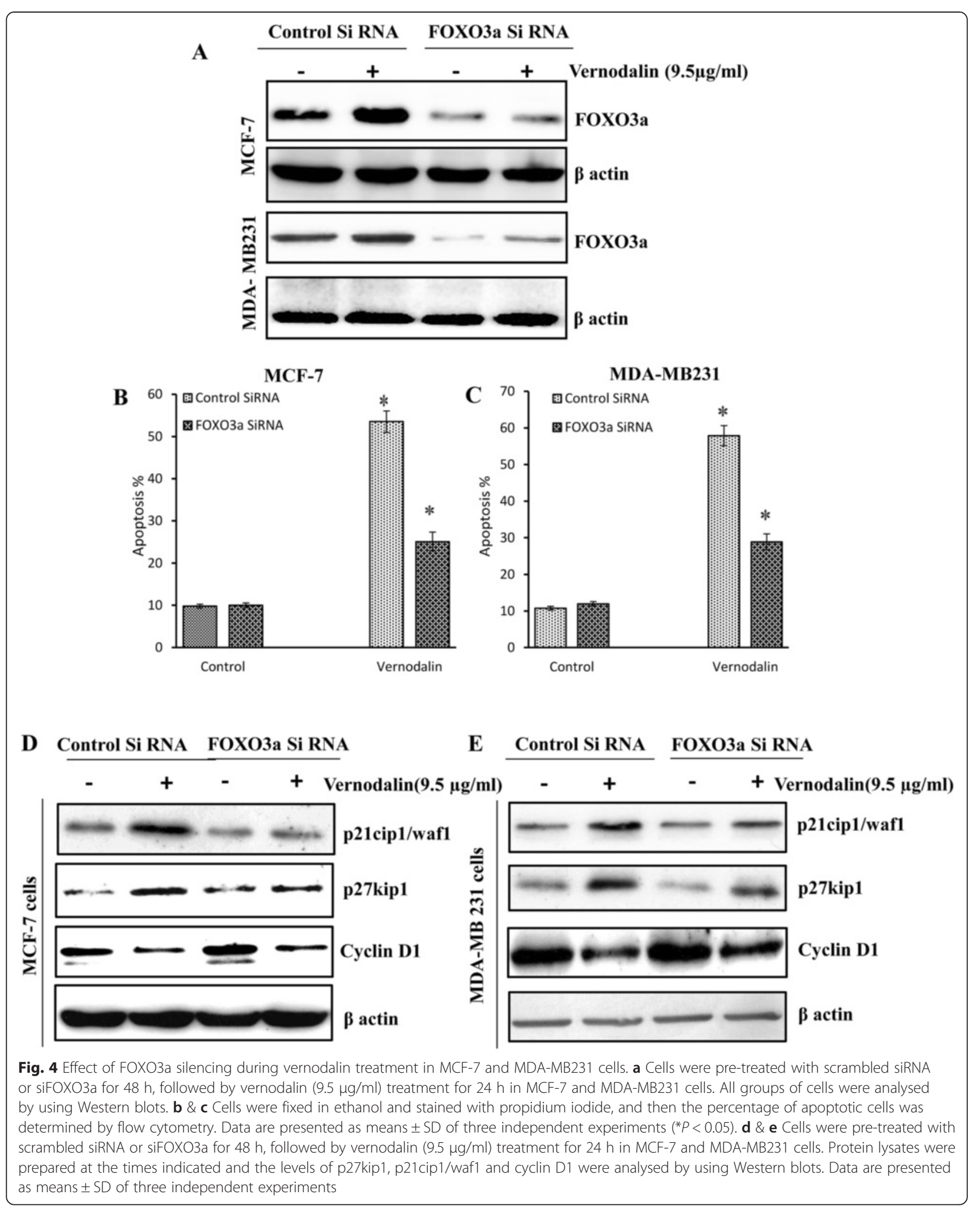




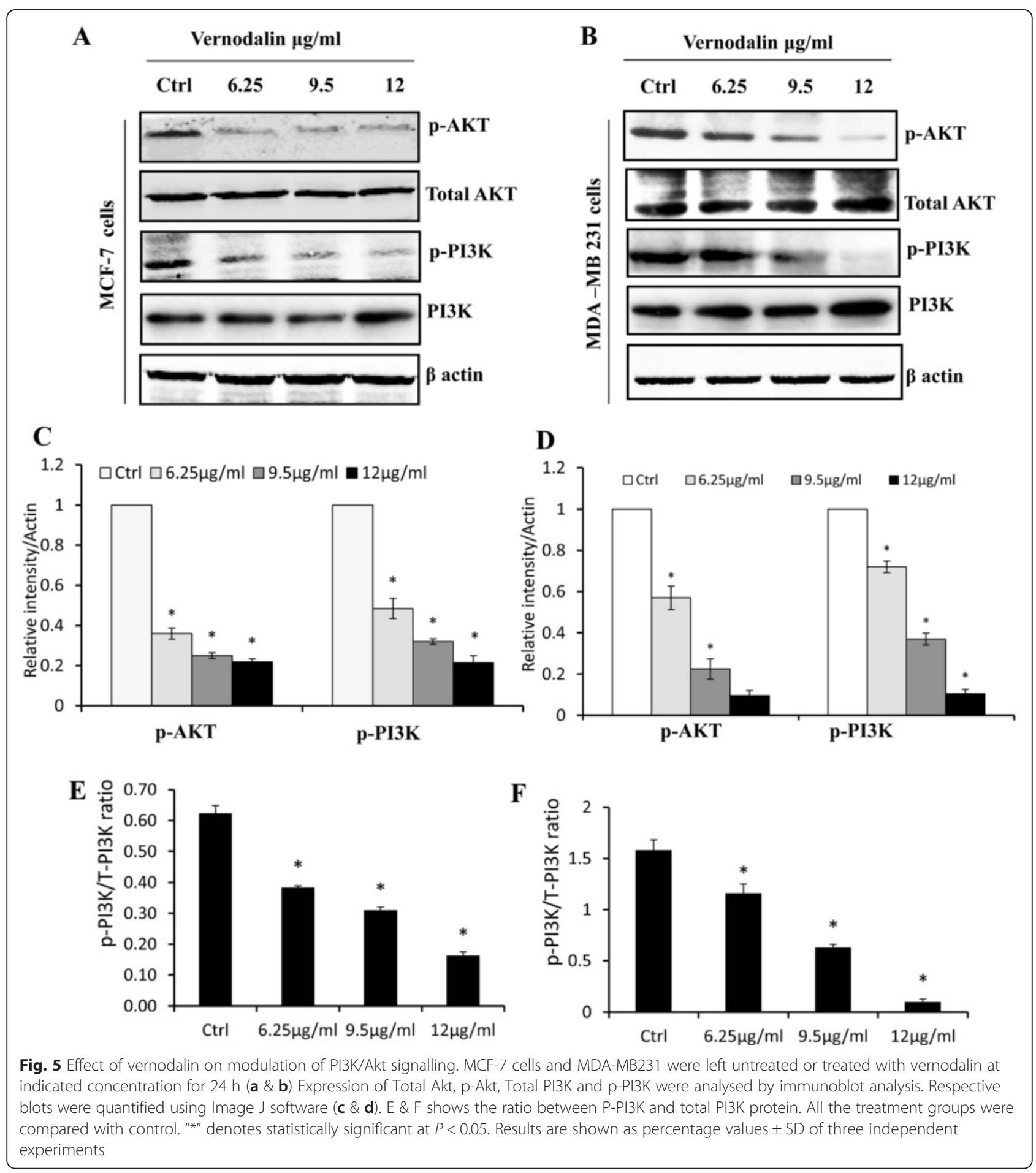

The tumor volume in untreated LA7 breast tumor bearing rats was enlarged up to $2143 \pm 363 \mathrm{~mm}^{3}$, whereas a significant decrease in tumor volume $\left(1182 \pm 352 \mathrm{~mm}^{3}, 524 \pm 261 \mathrm{~mm}^{3}\right)$ was observed in the treatment groups (low and high dose of vernodalin), comparable to the standard drug Tamoxifentreated group $562 \pm 145 \mathrm{~mm}^{3}$ (Table 1).
Vernodalin inhibited rat breast tumor growth in vivo by targeting FOXO3a

To assess the proliferation rate of breast tumor cells, the proliferation indexes were evaluated by Ki-67 and PCNA staining. The untreated LA7 breast tumor bearing rats (Group II) revealed intensive staining of PCNA and Ki-67 (Fig. 6), whereas, the vernodalin treated animals (Group 
Table 1 Treatment effect of vernodalin and TAM on animal body weight $(\mathrm{g})$, tumor volume $\left(\mathrm{mm}^{3}\right)$ and tumor reduction percentage (\%) in LA-7-induced breast cancer rats

\begin{tabular}{lllll}
\hline Group & Treatment groups & Body weight $(\mathrm{g})$ & Tumor volume $\left(\mathrm{mm}^{3}\right)$ & Tumor reduction percentage (\%) \\
\hline I & NC & $247.3 \pm 1.5$ & 0 & $0 \%$ \\
II & TC & $213.13 \pm 1.32$ & $2143 \pm 363$ & $0 \%$ \\
III & TT (1 mg/kg vernodalin) & $219.14 \pm 7.2$ & $1182 \pm 352^{*}$ & $44.84 \%$ \\
IV & TT (10 mg/kg vernodalin) & $221.57 \pm 5$ & $524 \pm 261^{*}$ & $75.6 \%$ \\
$V$ & TT (1 mg/kg TAM) & $224.88 \pm 5.7$ & $562 \pm 145^{*}$ & $73.78 \%$ \\
\hline
\end{tabular}

Each value represents mean \pm S.D. of given number of animals $(n=5)$. "** denotes statistically significant at $p<0.05$ compared to control group

III and IV; low and high dose respectively) exhibited a substantial decrease in the numbers and intensity of cell proliferation markers such as Ki67 and PCNA, comparable to a standard drug, Tamoxifen (Group V). As we showed that vernodalin could inhibit phosphorylation of FOXO3a in vitro, next we examined the phosphorylation status of FOXO3a and total FOXO3a protein in tumor tissues by immunohistochemistry. Treatment of rats with vernodalin inhibited the phosphorylation of FOXO3a and increases the total FOXO3a protein levels as compared to untreated control (Fig. 7). Since cell cycle inhibitor p27Kip1 is one of the targets of the FOXO transcription factor, we next examined the effect of vernodalin on the expression of p27Kip1 (Fig. 7). Immunohistochemistry
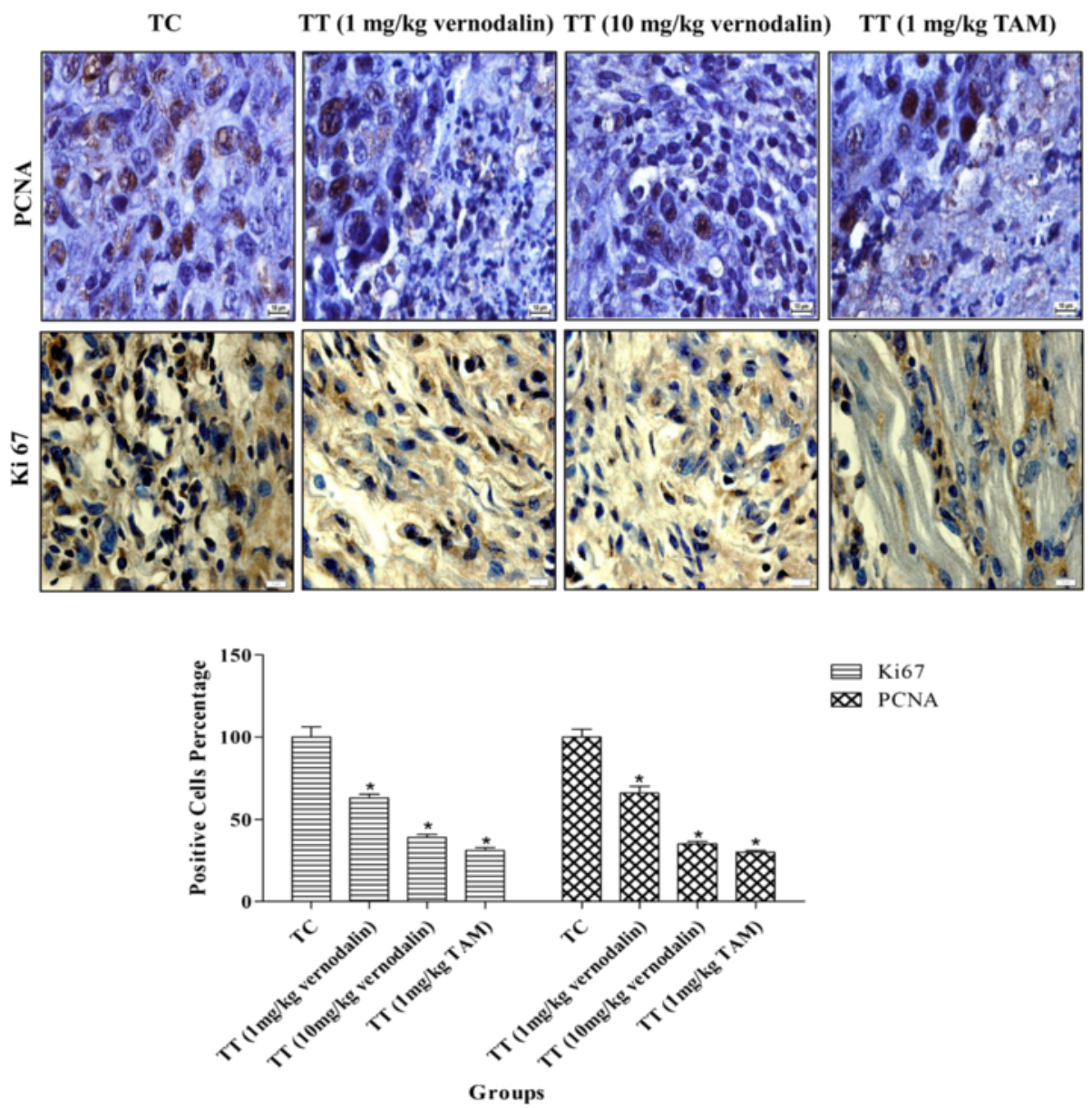

Fig. 6 Effect of vernodalin treatment on proliferation markers (Ki-67 and PCNA) in breast tumor tissue. Sprague dawley rats were implanted with LA7 cells. Rats were treated with low and high dose of vernodalin (1 or $10 \mathrm{mg} / \mathrm{kg}$ ) and the standard drug Tamoxifen (1 mg/kg). Tumor tissues were collected in $10 \%$ formalin and blocks were prepared in paraffin and immunohistochemistry of PCNA and Ki67 were performed as described in "Materials and Methods". Photomicrographs show representative pictures from five independent tumor samples. Bar $=10 \mu \mathrm{m}$. Quantification of Ki-67 and PCNA positive cells in tumor tissues was shown $\left({ }^{*} P<0.05\right)$ 


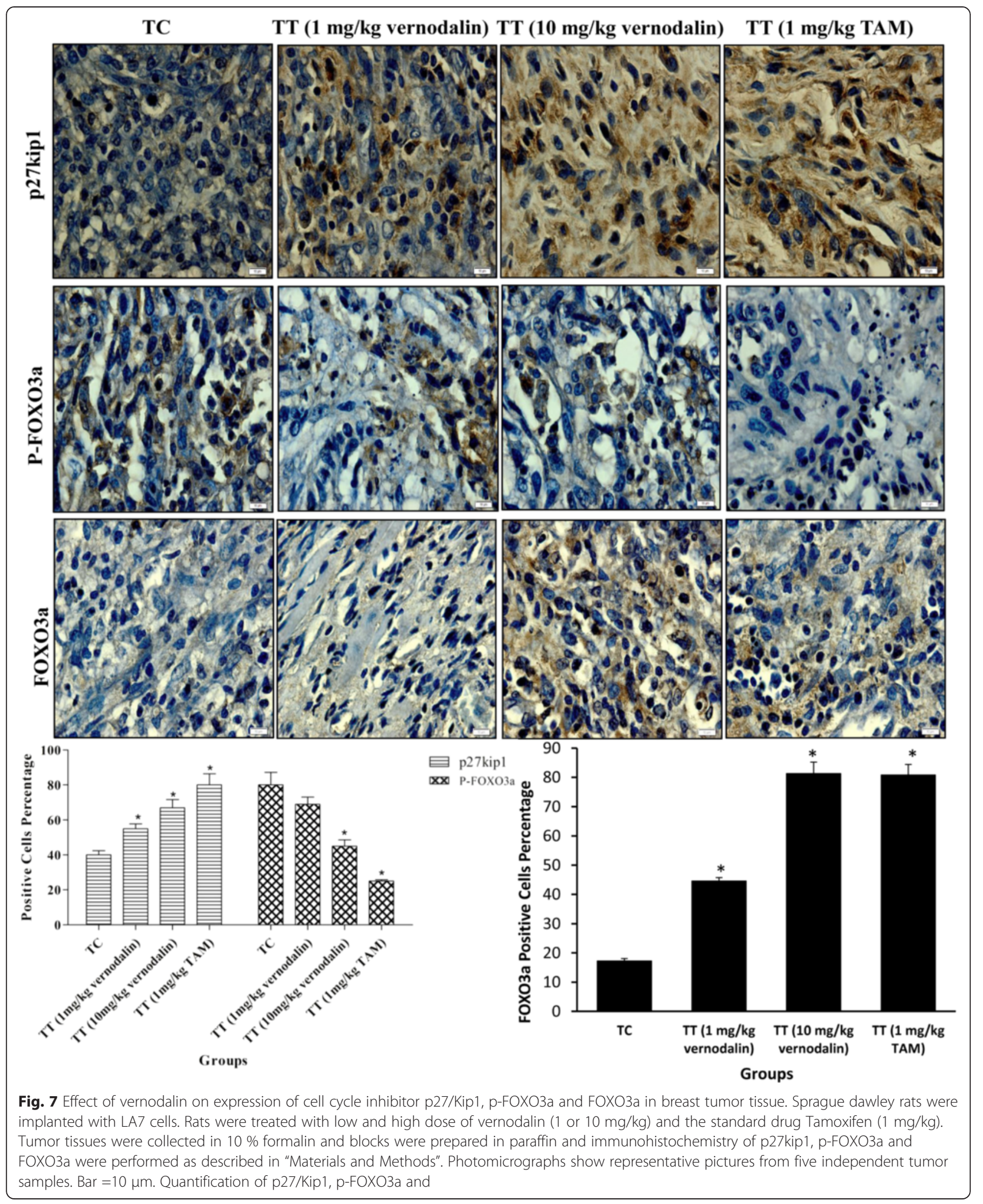


result reveals that p27Kip1 expression is higher in rats treated with low and high dose vernodalin (Group III and IV) compared with untreated LA7 tumor bearing animals (Group II). These data suggest that vernodalin can cause growth arrest in tumor cells in vivo by inducing the expression of FOXO3a and p27Kip1.

\section{Discussion}

Dysregulated proliferation is one of the main mechanisms for breast tumorigenesis, which involves different stages such as initiation, promotion and progression of tumor growth, thereby increasing the tumor burden and the increase the chances of metastasis. This dysregulation mainly occurs due to disrupted G1/S phase cell cycle transition during malignant neoplasm development [42]. Recently, research on the therapeutic activities of natural products in cancer therapy with diverse roles and targets are gaining attention [43-45]. Our previous studies revealed that vernodalin isolated from $C$. anthelminticum seeds possess anticancer property in breast and skin cancer model [37, 46]. However, the precise mechanism whereby vernodalin influences apoptosis in breast cancer remains unclear. FOXO transcription factors play an important role in tumor suppression by upregulation of pro-apoptotic genes, such as Bim and p27Kip1 in various tumors [47-50]. In this study, we evaluated the expression of FOXO3a and other important cell cycle molecules in response to vernodalin treatment. Subsequently, we examined the effect of vernodalin on PI3K/Akt pathway and provided evidences showing that FOXO3a activation could inhibit breast cancer cell proliferation and tumorigenesis.

Cell-cycle dysregulation is an attribute of tumor cells, thus cell-cycle arrest has become the major focus of anti-cancer effects. Anti-tumor agents can cause cell cycle arrest in various phases by regulating the cell-cycle machinery [51]. We previously reported that vernodalin induced cell cycle arrest at G0/G1 stage in breast cancer cells [37]. In the present study, we observed loss of cyclin D1, cyclin E expression and upregulation of $\mathrm{p} 21$ and p27 levels during vernodalin treatment. The p21 and p27 belong to the Cip/Kip family negatively regulate the cell cycle progression through inhibition of CDK-cyclin complexes [52]. On the other hand, cyclin D1 and cyclin $\mathrm{E}$ are major cell cycle regulatory proteins and mainly involved in the G1/S phase transition in normal cells. Over expression of these cyclin altered the cell cycle progression and closely associated with malignancy. The dysregulated cell proliferation plays an important role in multistage oncogenesis, which could caused by over expression of cyclins D1, E, and CDK4 complexes [53, 54]. The G1/S-phase transition is tightly regulated by CDKIs such as p21 and p27 via inactivation of G1 (CDK) complexes $[55,56]$. Taken together, our data reveal a novel cell cycle regulating property of vernodalin via G1-phase arrest.

Apoptotic cell death is a complex program mainly controlled by the Bcl- 2 family proteins. We previously reported that the apoptosis induction in vernodalintreated MCF-7 and MDA-MB231 cells is associated with upregulation of $\mathrm{Bax}$ (a Bcl-2 family member), cytochrome c release and caspases activation [37]. However, it was known that the presence of BH3-only molecules like Bim is required for direct activation of Bax at the mitochondria. In this study, we observed an increase in the protein expression of Bim after vernodalin treatment in breast cancer cells (Fig. 1a and b). Bim was also shown to be a direct downstream target of FOXO3a [57]. It is widely known for its pro-apoptotic functions in mitochondria and it can induce apoptosis by interacting with proteins such as $\mathrm{Bcl}-\mathrm{xL}$ and $\mathrm{Bcl}-2$ that shows anti-apoptotic function [58]. PI3K/Akt pathway is a cell survival pathway that is important for normal cell growth and proliferation. Numerous researches in breast cancer have shown that deregulation of this pathway is implicated in tumorigenesis and hence this has become an important target for breast cancer treatment. Notably, this pathway regulates the development and progression of human breast cancer by modulating the status of anti-apoptotic proteins, by mediating cell cycle arrest and inhibiting aerobic glycolysis via Akt which would preferentially kill tumor cells via oxidative stress $[56,59]$. As the amplification of PI3K/Akt signal transduction is the main force that drives cellular growth, thus abrogation of PI3K or Akt function might be crucial for cancer therapy. Of note, phosphorylated Akt is an attractive molecular target because it contributes to the development of breast cancer and confers resistance to conventional therapies [60] In this study, we observed decreased expression of p-Akt and p-PI3K after vernodalin treatment in both breast cancer cell-lines (Fig. 5) and this was further confirmed by in vitro kinase assay of Akt showed diminished phosphorylation of fusion protein GSK in vernodalin treated breast cancer cells and reflects the inhibitory effect of vernodalin on Akt kinase which clearly demonstrated that nuclear localization of FOXO3a was dependent on Akt signalling [61]. GSK3 $\beta$ is reported to regulate cell cycle analysis and apoptosis, Akt prevents the apoptotic activity of GSK3 $\beta$ by phosphorylation [62]. Our results suggested that vernodalin reflects the decrease in the Akt kinase activity as evaluated by the phosphorylation of GSK-3 $\beta$ protein as shown in (Additional file 4: Figure S4).

FOXO3a is an important downstream effector of the PI3K/Akt pathway. These proteins have emerged as major regulators that control cellular activities, through the orchestration of different patterns of gene expression in response to diverse stimuli [63]. Activation of Akt leads to phosphorylation of FOXO3a, resulting in its 
deactivation through nuclear export, while inhibition of Akt leads to dephosphorylation, nuclear localization and activation of FOXO3a [64]. The cytosolic retention of FOXO3a prevents the transactivation of downstream target genes such as Bim and p27Kip1. We hypothesized that the inhibition of Akt phosphorylation by vernodalin would lead to nuclear accumulation of FOXO3a and increased transcription of downstream responsive genes. Studies have shown that FOXO3a is dephosphorylated and activated by LY294002 (a potent inhibitor of PI3K), which correlates with upregulation of p27Kip1 [65]. It has been previously demonstrated that FOXO3a pathway can induce Bim expression and subsequently causing cell death in cancer models, such as MCF-7, mice xenografts model of pancreas tumor and lymphoma cells [66-68]. In agreement with the hypothesis, our study provides clear evidence that vernodalin treatment resulted in the activation (Fig. 1) and nuclear translocation (Fig. 3, Additional file 2: Figure S2 \& Additional file 3: Figure S3) of FOXO3a in breast cancer cells via PI3K/ Akt inhibition (decrease phosphorylation status of PI3K/ Akt and increase translocation of FOXO3a to the nucleus). Furthermore, silencing of the endogenous FOXO3a expression by siRNA rescued the breast carcinoma cells from undergoing proliferative arrest and apoptosis in response to vernodalin treatment, suggesting that the induction of FOXO3a expression has a direct role in mediating the effect of vernodalin. Transiently silenced FOXO3a also reversed the down-regulation of p21Cip1 and p27Kip1 cell cycle inhibitory proteins and increased cyclinD1 during vernodalin treatment in MCF-7 and MDA-MB 231cells (Fig. 4). These findings indicate that silencing of FOXO3a and vernodalin treatment in breast cancer cells modulates the expression of cyclinD1, p21Cip and p27Kip1 is FOXO3a/PI3K/Akt dependent manner. These results are consistent with previous published data showing that lapatinib also targets FOXO3a in breast cancer cells to induce apoptosis [69]

For in vivo study, we used rat mammary tumor cells (LA7) to induce mammary tumors in the right flank of rats to produce malignancy. Using this method, the mammary gland tumor developed within 7-10 days at the site of injection [70]. Current findings indicate that the applied low $(1 \mathrm{mg} / \mathrm{kg})$ or high $(10 \mathrm{mg} / \mathrm{kg})$ vernodalin dosages did not produce any toxicity sign in rats. Using these dosages, we observed a significant decrease in tumor volume in treatment groups, indicating vernodalin could suppress breast tumor growth in vivo. The result was comparable to a standard drug tamoxifen, which has been widely used for the treatment of breast cancer [71]. The anti-proliferative action of vernodalin was further confirmed using cell proliferative markers, namely PCNA and Ki67. PCNA (cell cycle related protein) is synthesized in early G1 to S-phase function in the cell cycle progression; DNA replication and repair [72]. Whereas Ki67 (nuclear protein) is required for maintaining cell proliferation and commonly used to evaluate the solid tumor cell proliferation [73]. In the current study, we observed increased expression of PCNA and Ki67 in breast tissue of control/untreated group. Concomitantly, these proliferative markers expression was efficiently decreased after vernodalin treatment (Fig. 6), indicating the inhibition of mammary gland tumorigenesis. Moreover, vernodalin induced the expression of FOXO3a protein and their target genes p27Kip1 in breast tumor tissues and decrease the level of p-FOXO3a protein, consistent with our in vitro studies (Fig. 7). These findings prove that vernodalin can inhibit the cell proliferation and breast carcinogenesis through G1/S phase cell cycle arrest. A schematic representation of vernodalin mechanism is shown in Fig. 8.

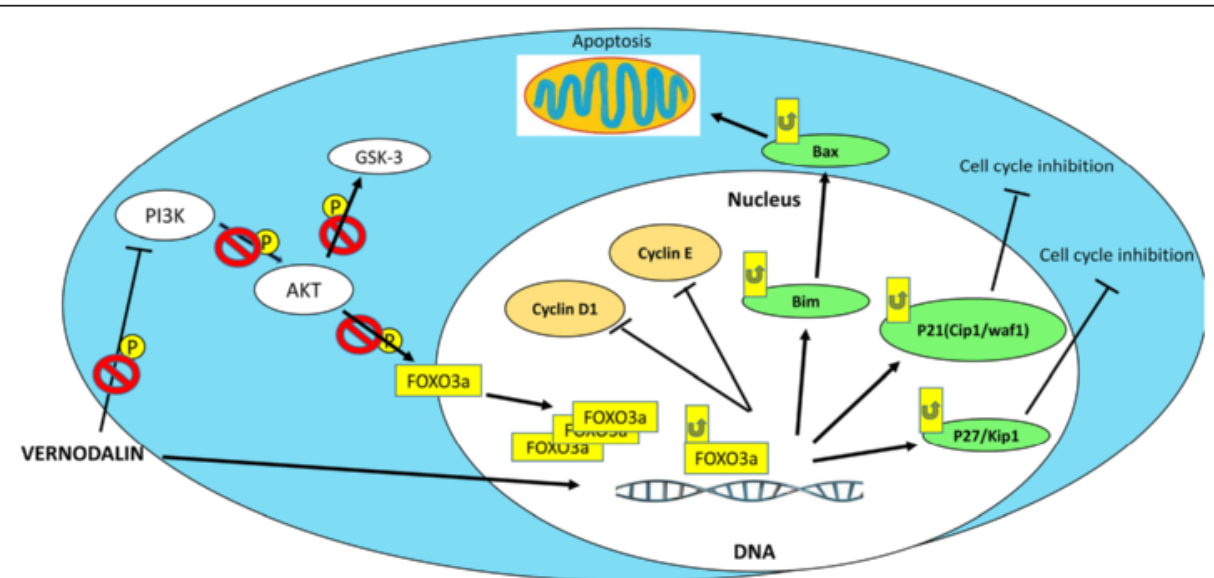

Fig. 8 Schematic representation of mechanisms underlying vernodalin-induced cytotoxicity in breast cancer cells. Vernodalin treatment inhibits the activation of PI3K/Akt pathway, which enhances accumulation of nuclear FOXO3a in MCF-7 and MDA-MB231 cells. Nuclear FOXO3a promotes the transcription and expression of Bim, which could activate Bax and causes cell death or apoptosis. On the other hand, FOXO3a upregulates p21Cip1/waf1, p27Kip1, downregulates cyclin D1 and cyclin E leading to cell cycle arrest 


\section{Conclusion}

It is obvious that vernodalin interferes with cellular processes by targeting different intracellular molecules. Using in vitro breast cancer cell-line model, we demonstrated that the cytotoxicity of vernodalin is mediated through FOXO3a activation. In addition, in vivo experiments reveal that vernodalin inhibits rat breast tumor growth by targeting FOXO3a and its downstream molecule, p27Kip1. Our results suggest that a combination of PI3K/Akt/FOXO signaling pathway is responsible for the cytotoxicity of vernodalin against breast cancer cells and this could also serve as a new target gene for the therapeutic or preventive intervention in breast cancer as well as other cancer typologies.

\section{Additional files}

Additional file 1: Figure S1. Chemical structure of Vernodalin. (JPG $130 \mathrm{~kb}$ )

Additional file 2: Figure S2. Vernodalin treatment induces FOXO3a nuclear translocation in MCF-7 cells. MCF-7 cells were treated with DMSO (control) or indicated concentration of vernodalin for $24 \mathrm{~h}$. Immunofluorescent staining was then performed using the FOXO3a antibody (green) and stained with Hoechst 33258 (blue). Images were acquired using cellomic HCS array scan reader (objective 20X). Representative figures (control, 6.25, $9.5 \mu \mathrm{g} / \mathrm{ml}$ of vernodalin and Doxorubicin $3 \mu \mathrm{g} / \mathrm{ml}$ ) were shown. Bar chart shows average fluorescence intensities of $\mathrm{FOXO} 3 \mathrm{a}$ accumulation in the nucleus. Data were mean \pm SD of fluorescence intensity readings representative of three independent experiments. $\left({ }^{*} P<0.05\right)$. (JPG $536 \mathrm{~kb}$ )

Additional file 3: Figure S3. Vernodalin treatment induces $\mathrm{FOXO3a}$ nuclear translocation in MDA-MB-231 cells. MDA-MB231 cells were treated with DMSO (control) or indicated concentration of vernodalin for $24 \mathrm{~h}$. Immunofluorescent staining was then performed using the FOXO3a antibody (green) and stained with Hoechst 33258 (blue). Images were acquired using Cellomic HCS array scan reader (objective 20X). Representative figures (control, $6.25,9.5 \mu \mathrm{g} / \mathrm{ml}$ of vernodalin and Doxorubicin $3 \mu \mathrm{g} / \mathrm{ml}$ ) were shown. Bar chart shows average fluorescence intensities of FOXO3a accumulation in the nucleus. Data were mean \pm SD of fluorescence intensity readings representative of three independent experiments. ( $\left.{ }^{*} P<0.05\right)$. (JPG $573 \mathrm{~kb}$ )

Additional file 4: Figure S4. AKT kinase assay. Akt enzymatic activity was evaluated by phosphorylation of a GSK-3 fusion protein after immunoprecipitation of Akt using a nonradioactive Akt kinase kit as described in the Materials and Methods section. The relative intensity of the $\mathrm{p}-\mathrm{GSK} 3 \mathrm{a} / \mathrm{\beta}$ band reflected the AKT kinase activity and Total-AKT was immunoblotted as controls. GSK-3 phosphorylation bands were analysed densitometrically. All the treatment groups were compared with control. "*" denotes statistically significant at $P<0.05$. Results are shown as percentage values \pm SD of three independent experiments. (JPG $318 \mathrm{~kb}$ )

Additional file 5: Figure S5. Effect of FOXO3a-specific siRNA on expression of AKT and $\mathrm{p}-\mathrm{AKT}$ in response to vernodalin treatment in MCF-7 and MDA-MB231 cells. Cells were pre-treated with scrambled siRNA or siFOXO3a for $48 \mathrm{~h}$, followed by vernodalin $(9.5 \mu \mathrm{g} / \mathrm{ml})$ treatment for $24 \mathrm{~h}$ in MCF-7 and MDA-MB231 cells. Protein lysates were prepared at the times indicated and the levels of AKT and p-AKT were analysed by using Western blots. Data are presented as means \pm SD of three independent experiments. (JPG $255 \mathrm{~kb}$ )

Additional file 6: Figure S6. Histopathological study of kidney and liver tissues from control or vernodalin treated rats. A.control (untreated). B. vernodalin $1 \mathrm{mg} / \mathrm{kg}$ - treated. C. vernodalin $10 \mathrm{mg} / \mathrm{kg}$ treated. $(n=5)$. Liver sections of control and vernodalin treated rats showing normal architecture of hepatocytes with visible central vein and normal arrangement of hepatocytes. Kidney sections of control and vernodalin treated rats showing normal glomerular, tubular sections. Representative micrographs of histologic sections were shown at 20x magnification. (JPG $396 \mathrm{~kb}$ )

\section{Competing interests}

The authors have declared that no competing interest exists.

\section{Authors' contributions}

SKAS conceived and participated in the study design, supervision of laboratory processes, analysis and interpretation of the results, writing of the manuscript. NM conceived the study, participated in the design and carried out the molecular and SiRNA experiments. LCY participated and suggested the critical review of the manuscript. $\mathrm{MH}$ participated in the design and Immunofluorescence experiments. AKP assisted the molecular experiments and also the interpretation of data. AA and HM helped in animal experiments, and immunohistochemistry. MRM participated in the study design and critical review during the writing of manuscript. All authors read and approved the final manuscript.

\section{Acknowledgments}

The present study was financially supported by a High Impact research grant from the University of Malaya (E00002-20001) and University of Malaya research grant (UMRG RP027A-14HTM).

\section{Author details}

${ }^{1}$ Department of Pharmacology, Faculty of Medicine, University of Malaya, Kuala Lumpur 50603, Malaysia. ²Department of Biochemistry, Central Leather Research Institute, Council of Scientific and Industrial Research (CSIR), Adyar, Chennai 600 020, India. ${ }^{3}$ Department of Pharmacy, Faculty of Medicine, University of Malaya, Kuala Lumpur 50603, Malaysia.

Received: 7 August 2015 Accepted: 1 December 2015 Published online: 08 December 2015

\section{References}

1. Siegel R, Naishadham D, Jemal A. Cancer statistics. 2013. CA Cancer J Clin. 2013;63:11-30

2. Jemal A, Bray F, Center MM, Ferlay J, Ward E, Forman D. Global cancer statistics. CA Cancer J Clin. 2011;61:69-90.

3. Hanahan D, Weinburg RA. Hallmarks of cancer: the next generation. Cell. 2011;144:646-74.

4. Henderson BE, Feigelson HS. Hormonal carcinogenesis. Carcinogenesis. 2000;21:427-33.

5. Brunello A, Roma A, Falci C, Basso U. Chemotherapy and targeted agents for elderly women with advanced breast cancer. Recent Pat Anticancer Drug Discov. 2008;3:187-201.

6. Reuben SC, Gopalan A, Petit DM, Bishayee A. Modulation of angiogenesis by dietary phytoconstituents in the prevention and intervention of breast cancer. Mol Nutr Food Res. 2012;56:14-29.

7. Vadodkar AS, Suman S, Lakshmanaswamy R, Damodaran C. Chemoprevention of breast cancer by dietary compounds. Anticancer Agents Med Chem. 2012;12:1185-202.

8. Sarkar FH, Li YW. Targeting multiple signal pathways by chemopreventive agents for cancer prevention and therapy. Acta Pharmacol Sin. 2007;28: 1305-15.

9. Kado K, Forsyth A, Patel PR, Schwartz JA. Dietary supplements and natural products in breast cancer trials. Front Biosci. 2012;4:546-67.

10. Greenlee H, Kwan ML, Ergas IJ, Sherman KJ, Krathwohl SE, Bonnell C. Complementary and alternative therapy use before and after breast cancer diagnosis: the Pathways Study. Breast Cancer Res Treat. 2009;117:653-65.

11. Kumar NB, Allen K, Bell K. Perioperative herbal supplement use in cancer patients: potential implications and recommendations for presurgical screening. Cancer Control. 2005;12:149-57.

12. Huang H, Tindal DJ. Dynamic FoxO transcription factors. J Cell Sci. 2007;120: 2479-87.

13. van der Vos KE, Coffer PJ. The extending network of FOXO transcriptional target genes. Antioxid Redox Signal. 2011;14:579-92.

14. Jin GS, Kondo E, Miyake T, Shibata M, Takashima T, Liu YX, et al. Expression and intracellular localization of FKHRL1 in mammary gland neoplasms. Acta Med Okayama. 2014;58:197-205.

15. Fei $M$, Zhao $Y$, Wang $Y$, Lu M, Cheng C, Huang $X$. Low expression of Foxo3a is associated with poor prognosis in ovarian cancer patients. Cancer Invest. 2009;27:52-9. 
16. Su JL, Cheng X, Yamaguchi H, Chang YW, Hou CF, Lee DF. FOXO3adependent mechanism of E1A-induced chemosensitization. Cancer Res. 2011;71:6878-87.

17. Calnan DR, Brunet A. The FoxO code. Oncogene. 2008;27:2276-88.

18. Brunet A, Bonni A, Zigmond MJ, Lin MJ, Juo P, Hu LS. Akt promotes cell survival by phosphorylating and inhibiting a forkhead transcription factor. Cell. 1999;96:857-68.

19. Lin K, Dorman JB, Rodan A, Kenyon C. Daf-16: An HNF-3/forkhead family member that can function to double the life-span of Caenorhabditis elegans. Science. 1997;278:1319-22.

20. Accili D, Arden KC. FoxOs at the crossroads of cellular metabolism, differentiation, and transformation. Cell. 2004;117:421-6.

21. Burgering BM, Kops GJ. Cell cycle and death control: long live Forkheads. Trends Biochem Science. 2002;27:352-60.

22. Chen J, Yusuf I, Andersen HM, Fruman DA. FOXO transcription factors cooperate with delta EF1 to activate growth suppressive genes in $B$ lymphocytes. J Immunol. 2006;176:2711-21.

23. Rosas M, Birkenkamp KU, Lammers JW, Koenderman L, Coffer PJ. Cytokine mediated suppression of TF-1 apoptosis requires PI3K activation and inhibition of Bim expression. FEBS Lett. 2005;579:191-8.

24. Yang JY, Xia W, Hu MC. lonizing radiation activates expression of FOXO3a, Fas ligand, and Bim, and induces cell apoptosis. Int J Oncol. 2006;29:643-8.

25. Yang JY, Hung MC. A new fork for clinical application: targeting forkhead transcription factors in cancer. Clin Cancer Res. 2009;15:752-7.

26. Yang JY, Chang CJ, Xia W, Wang Y, Wong KK, Engelman JA, et al. Activation of FOXO3a is sufficient to reverse mitogen-activated protein/extracellular signal-regulated kinase inhibitor chemoresistance in human cancer. Cancer Res. 2010;70:4709-18.

27. Johansson M, Perssson JL. Cancer therapy: targeting cell cycle regulators. Anti-Cancer Agents Med Chem. 2008;8:723-31.

28. Sherr CJ, Roberts JM. CDK inhibitors: positive and negative regulators of G1-phase progression. Genes Dev. 1999;13:1501-12.

29. Franke TK. PI3K/Akt: getting it right matters. Oncogene. 2008;27:6473-88.

30. Saxena NK, Sharma D, Ding XK, Lin S, Marra F, Merlin D, et al. Concomitant activation of the JAKSTAT, PI3KNAKT, and ERK signaling is involved in leptinmediated promotion of invasion and migration of hepatocellular carcinoma cells. Cancer Res. 2007;67:2497-507.

31. Vivanco I, Sawyers CL. The phosphatidylinositol 3-Kinase AKT pathway in human cancer. Nat Rev Cancer. 2002;2:489-501.

32. Hennessy BT, Smith DL, Ram PT, LU Y, Mills GB. Exploiting the PI3K/AKT pathway for cancer drug discovery. Nat Rev Drug Discov. 2005;4:988-1004.

33. Arya A, Looi CY, Cheah SC, Mustafa MR, Mohd MA. Anti-diabetic effects of Centratherum anthelminticum seeds methanolic fraction on pancreatic cells, $\beta$-TC6 and its alleviating role in type 2 diabetic rats. Journal of Ethnopharmacol. 2012;144:22-32.

34. Sharma S, Mehta BK. in vitro antimicrobial efficacy of Centratherum anthelminticum seeds extracts. J Hyg Epidemiol Microbiol Immunol. 1991;35:157-61.

35. Singhal KC, Sharma S, Mehta BK. Antifilarial activity of Centratherum anthelminticum seed extracts on Setaria cervi. Indian J Exp Biol. 1992;30:546-8.

36. Arya A, Achoui M, Cheah SC, Abdelwahab SI, Narrima P, Mohan S, et al. Chloroform Fraction of Centratherum anthelminticum (L.) Seed Inhibits Tumor Necrosis Factor Alpha and Exhibits Pleotropic Bioactivities: Inhibitory Role in Human Tumor Cells. Evid Based Complement Alternat Med. 2012b;2012: 627256.

37. Looi CY, Arya A, Cheah FK, Muharram B, Leong KH, Mohamad K, et al. Induction of apoptosis in human breast cancer cells via caspase pathway by vernodalin isolated from Centratherum anthelminticum (L.) seeds. PLoS One. 2013;8:e56643.

38. Riveraa ES, Andradeb N, Martin G, Melito G, Cricco G, Mohamad N, et al. Induction of mammary tumors in rat by intraperitoneal injection of NMU: histopathology and estral cycle influence. Cancer Lett. 1994;86:223-8.

39. Carlsson G, Gullberg B, Hafstrom L. Estimation of liver tumor volume using different formulas-an experimental study in rats. J Cancer Res Clin Oncol. 1983;105:20-3.

40. Li Y, Wang Z, Kong D, Li R, Sarkar SH, Sarkar FH. Regulation of Akt/FOXO3a/ GSK-3beta/AR signaling network by isoflavone in prostate cancer cells. J Biol Chem. 2008;283:27707-16.

41. Qi W, Weber CR, Wasland K, Savkovic SD. Genistein inhibits proliferation of colon cancer cells by attenuating a negative effect of epidermal growth factor on tumor suppressor FOXO3 activity. BMC Cancer. 2011;11:219.
42. Andreeff M, Goodrich DW, Pardee AB, et al. Cell proliferation, differentiation, and apoptosis. In: Bast Jr RC, Kufe DW, Pollock RE, editors. Holland-Frei cancer medicine. 5th ed. Hamilton (ON): BC Decker; 2000

43. Hibasami H, Iwase H, Yoshioka K, Takahashi H. Glycyrrhizin induces apoptosis in human stomach cancer KATO III and human promyelotic leukemia HL-60cells. Int J Mol Med. 2005;16:233-6.

44. Rabi T, Shukla S, Gupta S. Betulinic acid suppresses constitutive and TNF alpha-induced NF-kappaB activation and induces apoptosis in human prostate carcinoma PC-3cells. Mol Carcinog. 2008;47:964-73.

45. Zheng F, Wu J, Zhao S, Luo Q, Tang Q, Yang L, et al. Baicalein increases the expression and reciprocal interplay of RUNX3 and FOXO3a through crosstalk of AMPKa and MEK/ERK1/2 signaling pathways in human non-small cell lung cancer cells. J Exp Clin Cancer Res. 2015; 7: 34:41.

46. Looi CY, Moharram B, Paydar M, Wong YL, Leong KH, Mohamad K, et al. Induction of apoptosis in melanoma A375 cells by a chloroform fraction of Centratherum anthelminticum (L.) seeds involves NF-kappaB, p53 and BCl-2controlled mitochondrial signaling pathways. BMC Complement Altern Med. 2013;13:166.

47. Tzivion G, Dobson M, Ramakrishnan G. FoxO transcription factors: regulation by AKT and 14-3-3 proteins. Biochim Biophys Acta. 1813; 2011:1938-45

48. Zanella F, Link W, Carnero A. Understanding FOXO, new views on old transcription factor. Curr Cancer Drug Targets. 2010;10:135-46.

49. Hong ZY, Lee HJ, Shin DY, Kim SK, Seo M, Lee EJ. Inhibition of Akt/FOXO3a signaling by constitutively active FOXO3a suppresses growth of follicular thyroid cancer cell lines. Cancer Lett. 2012;314:34-40.

50. Roy SK, Chen Q, Fu J, Shankar S, Srivastava RK. Resveratrol inhibits growth of orthotopic pancreatic tumors through activation of FOXO transcription factors. PLoS One. 2011;6:e25166.

51. Stewart AZ, Westfall MD, Pietenpol JA. Cell-cycle dysregulation and anticancer therapy. Trends Pharmacol Sci. 2003;24:139-45.

52. Labaer J, Garrett MD, Stevenson LF, Slingerland JM, Sandhu C, Chou HS. New functional activities for the p21 family of CDK inhibitors. Genes Dev. 1997;11:847-62.

53. Kim JK, Diehl JA. Nuclear cyclin D1: an oncogenic driver in human cancer. J Cell Physiol. 2009;220:292-6.

54. Lapenna S, Giordano A. Cell cycle kinases as therapeutic targets for cancer. Nat Rev Drug Discov. 2009:8:547-66.

55. Vermeulen K, Van Bockstaele DR, Berneman Z. The cell cycle: a review of regulation, deregulation and therapeutic targets in cancer. Cell Prolif. 2003; 36:131-49.

56. Castaneda CA, Cortes-Funes H, Gomez HL, Ciruelos EM. The phosphatidy inositol 3-kinase/AKT signaling pathway in breast cancer. Cancer Metastasis Rev. 2010;29:751-9.

57. Dijkers PF, Medema RH, Lammers JW, Koenderman L, Coffer PJ. Expression of the pro-apoptotic $\mathrm{BCl}-2$ family member Bim is regulated by the forkhead transcription factor FKHRL1. Curr Biol. 2000;10:1201-4.

58. O'Connor LO, Strasser A, O'Reilly LA, Hausmann G, Adams JM, Cory S, et al. Bim: a novel member of the $\mathrm{BCl}-2$ family that promotes apoptosis. EMBO J. 1998;17:384-95.

59. Liu W, Bagaitkar J, Watabe K. Roles of AKT signal in breast cancer. Front Biosci. 2007;12:4011-9.

60. Obaya AJ, Sedivy JM. Regulation of cyclin-Cdk activity in mammalian cells. Cell Mol Life Sci. 2002;59:126-42.

61. Zhang X, Tang N, Hadden TJ, Rishi AK. Akt, FoxO and regulation of apoptosis. Biochim Biophys Acta. 1813;2011:1978-86.

62. Huang L, Wu SN, Xing D. High fluence low-power laser irradiation induces apoptosis via inactivation of Akt/GSK3 beta signaling pathway. J Cell Physiol. 2011;226:588-601.

63. Carter ME, Brunet A. FOXO transcription factors. Curr Biol. 2007;17:R113-4.

64. Weng SC, Kashida Y, Kulp SK, Wang D, Brueggemeier RW, Shapiro CL, et al. Sensitizing estrogen receptor-negative breast cancer cells to tamoxifen with OSU-03012, a novel celecoxib-derived phosphoinositide-dependent protein kinase-1/Akt signaling inhibitor. Mol Cancer Ther. 2008;7:800-8.

65. Chandramohan V, Jeay S, Pianetti S, Sonenshein GE. Reciprocal control of Forkhead boxO3a and c-Myc via the phosphatidylinositol 3-kinase pathway coordinately regulates p27Kip1 levels. J Immunol. 2004;172: 5522-7.

66. Sharma G, Kar S, Palit S, Das PK. 18ß-glycyrrhetinic acid induces apoptosis through modulation of Akt/FOXO3a/Bim pathway in human breast cancer MCF-7 cells. J Cell Physiol. 2011;227:1923-31. 
67. Boreddy SR, Pramanik KC, Srivastava SK. Pancreatic tumor suppression by benzyl isothiocyanate is associated with inhibition of PI3K/AKT/FOXO pathway. Clin Cancer Res. 2011;17:1784-95.

68. Bhalla S, Evens AM, Dai B, Prachand S, Gordon LI, Gartenhaus RB. The novel antiMEK small molecule AZD6244 induces BIM-dependent and AKT-independent apoptosis in diffuse large B-cell lymphoma. Blood. 2011;118:1052-61.

69. Krol J, Francis RE, Albergaria A, Sunters A, Polychronis A, Coombes RC, et al. The transcription factor FOXO3a is a crucial cellular target of gefitinib (Iressa) in breast cancer cells. Mol Cancer Ther. 2007;12:3169-79.

70. Kim SA, Kim HW, Kim DK, Kim SG, Park JC, Kang DW, et al. Rapid induction of malignant tumor in Sprague Dawley rats by injection of RK3E-ras cells. Cancer Lett. 2006;235:53-9.

71. Jordan VC. A current view of tamoxifen for the treatment and prevention of breast cancer. Br J Pharmacol. 1993;110:507-17.

72. Huawei Z, Davis CD. Down-regulation of proliferating cell nuclear antigen gene expression occurs during cell cycle arrest induced by human fecal water in colonic HT-29 cells. J Nutr. 2003;133:2682-7.

73. Fitzgibbons P1, Page DL, Weaver D, Thor AD, Allred DC, Clark GM, et al. Prognostic factors in breast cancer. College of American Pathologists Consensus Statement 1999. Arch Pathol Lab Med. 2000;124:966-78.

Submit your next manuscript to BioMed Central and we will help you at every step:

- We accept pre-submission inquiries

- Our selector tool helps you to find the most relevant journal

- We provide round the clock customer support

- Convenient online submission

- Thorough peer review

- Inclusion in PubMed and all major indexing services

- Maximum visibility for your research 